\title{
Pleomorphic Adenoma of Nasal Cavity: A Rare Case Report
}

\author{
${ }^{1}$ Sushant Joshi, ${ }^{2} \mathrm{HS}$ Bhuie, ${ }^{3}$ Navneet Mathur, ${ }^{4}$ Hitesh Verma
}

\begin{abstract}
Pleomorphic adenomas are most common benign tumor of the major salivary gland, mainly found in parotid gland. Pleomorphic adenomas may also occur in the minor salivary glands of the hard and soft palate. Few cases are also diagnosed in various parts of pharynx and larynx. Intranasal pleomorphic adenomas can arise either from septum or lateral nasal wall. They are very rare entity and occasionally misdiagnosed due to their atypical histopathology. We present a rare case of pleomorphic adenoma diagnosed in middle-aged female originating from lateral wall of right nasal cavity.
\end{abstract}

Keywords: Pleomorphic adenoma, Nasal cavity, Excision, Endoscopic.

How to cite this article: Joshi S, Bhuie HS, Mathur N, Verma H. Pleomorphic Adenoma of Nasal Cavity: A Rare Case Report. Clin Rhinol An Int J 2014;7(2):67-69.

\section{Source of support: Nil}

Conflict of interest: None declared

\section{INTRODUCTION}

Salivary gland tumors constitute about $3 \%$ of all body neoplasms. ${ }^{1,2}$ The majority of these tumors are benign and about $70 \%$ of them are pleomorphic adenomas. Minor salivary glands are involved in only 6.5 to $8 \%, 3,4$ and mainly involve hard and soft palate; however, pleomorphic adenoma of the nasal cavity are rare. ${ }^{5-7}$

In this paper, we report a case of pleomorphic adenoma of lateral wall of right nasal cavity treated successfully by endoscopic resection.

\section{CASE REPORT}

A 35 years old female complained of progressive right nasal obstruction with mucoid rhinorrhea and occasional nasal bleeding for last 5 months. On anterior rhinoscopy, red fleshy polypoidal mass was filling right nasal cavity

\footnotetext{
${ }^{1}$ Senior Resident, ${ }^{2}$ Professor and Head, ${ }^{3,4}$ Assistant Professor

${ }^{1-4}$ Department of Otorhinolaryngology and Head and Neck Surgery, Rabindranath Tagore Medical College, Udaipur Rajasthan, India
}

Corresponding Author: Sushant Joshi, Senior Resident Department of Otorhinolaryngology and Head and Neck Surgery, Rabindranath Tagore Medical College, Udaipur Rajasthan, India, e-mail: dr_sushantjoshi@yahoo.co.in completely with deviation of anterior part of septum left side. Other routine laboratory examinations were normal. The contrast-enhancing computed tomography (CT) scan of nose and paranasal sinuses showed homogenous mass filling the anterior aspect of right nasal cavity and displacing septum to left side with minimal superior extension into anterior ethmoidal cells (Figs 1A and B). The right maxillary sinus was normal.

Wide excision of mass was performed endoscopically under general anesthesia. During surgery, the soft, pinkish mass was found to be attached to the lateral nasal wall (Fig. 2). After confirming its attachment, the mass was cauterized at the base and removed from nasal cavity. Hemostasis was achieved, and nasal packing was done. The histopathological examination showed features of salivary pleomorphic adenoma (Figs 3A and B). After one year of follow-up, no recurrence seen.

\section{DISCUSSION}

The most common tumors of the major salivary glands are pleomorphic adenomas, but in rare cases, they can occur in minor salivary glands located in respiratory tract. Denker and Kahler were the first to report the case of pleomorphic adenoma in nose. ${ }^{8}$ Nasal cavity is the most favored site for development of pleomorphic adenoma in upper respiratory tract followed by maxillary sinus and nasopharynx. ${ }^{9}$ Nasal septum is the most common site of origin followed by lateral nasal wall. Pleomorphic adenoma of nose is more common in third to sixth decade and more frequently seen in females. Typical presenting complaints include unilateral nasal obstruction and epistaxis seen in 71 and $56 \%$ respectively. Mass in the nose, nasal swelling, epiphora and mucopurulent rhinorrhea are other presenting features. ${ }^{10}$ Histologically, pleomorphic adenomas are characterized by epithelial tissue mixed with tissues of mucoid, myxoid or chondroid appearance. Nasal pleomorphic adenomas are characterized by predominant epithelial component and scanty stromal tissue and thus, histologically, they resemble aggressive epithelial tumors and therefore often misdiagnosed. ${ }^{2}$ The contrast enhancing CT scan of the nose and paranasal sinuses reveals a lobulated soft tissue density mass arising from either septum or lateral wall of nose.

Endoscopic resection of tumor is treatment of choice now days as this technique causes less morbidity, hospital stay, 


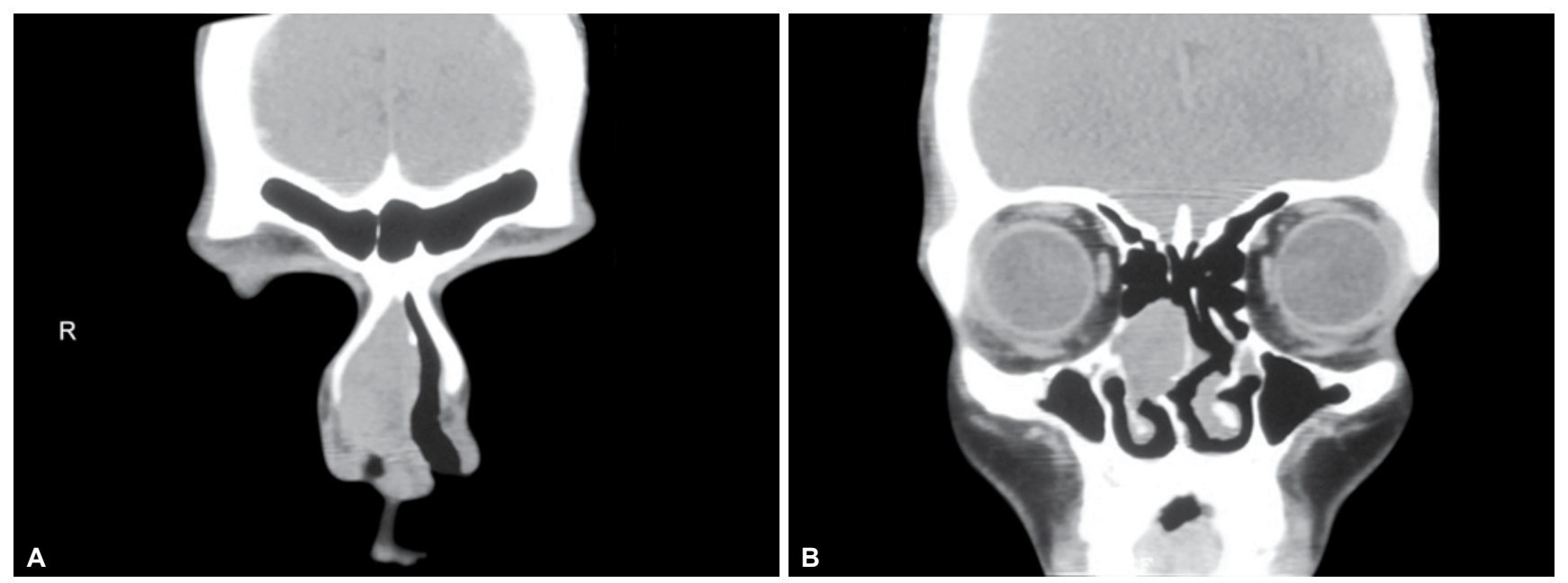

Figs $1 \mathrm{~A}$ and $\mathrm{B}$ : Serial coronal CT scan showing homogeneous mass filling the anterior aspect of right nasal cavity and displacing septum to left side

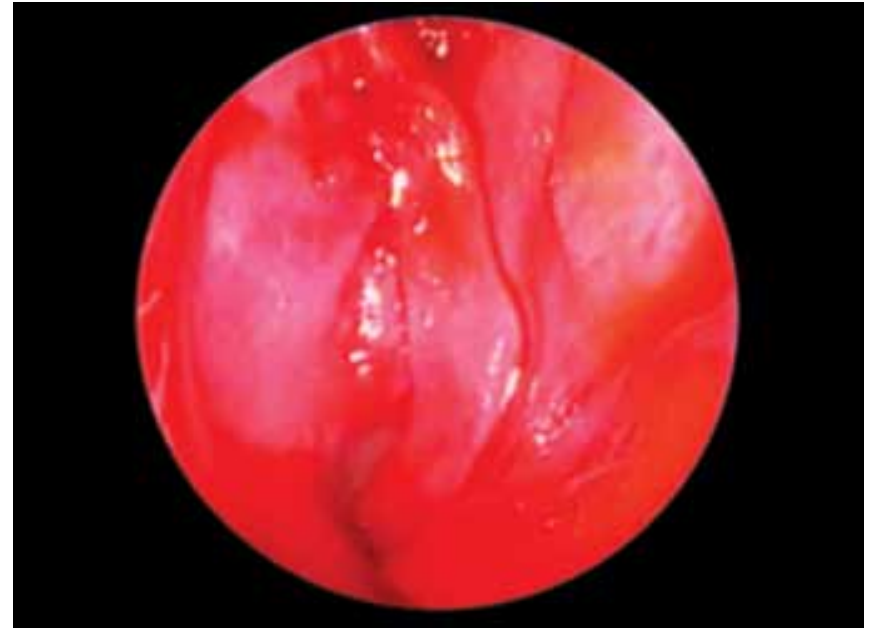

Fig. 2: Intraoperative picture showing pinkish soft mass in anterior nasal cavity attached to lateral nasal wall
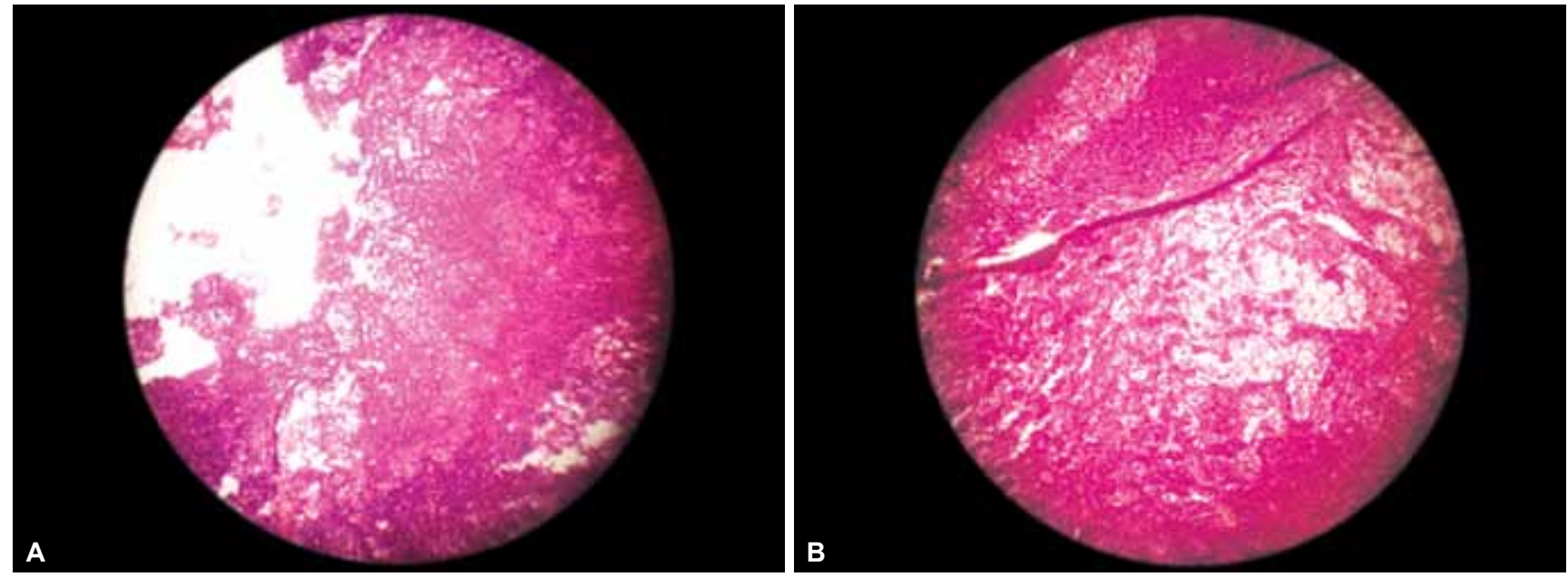

Figs 3 A and B: Histopathological picture showing epithelial/myoepithelial areas punctuated by myxochondroid areas

avoids external scar and unnecessary excessive resection. ${ }^{5,6}$ To avoid recurrences, the tumor must be removed with histologically tumor negative margins as recurrence rate ranges from 2.4 to $7.5 \%{ }^{10,11}$ Recurrence is thought to be due to detachment of small projections through the incomplete capsule or tumor spillage during the operation. ${ }^{14}$
Prognosis for intranasal pleomorphic adenoma is better than those in other unusual sites in upper respiratory tract, as they show early symptoms leading to an early diagnosis and management. $^{12}$

Neoplasms arising from nasal septum have more chances of malignant transformation than other sites in nasal cavity. ${ }^{13}$ 
Malignant pleomorphic adenoma can metastasize to distant organs, such as bone, lung, regional lymph nodes and liver.

\section{REFERENCES}

1. Jassar P, Stafford N, Macdonald A. Pleomorphic adenoma of the nasal septum. J Laryngol Otol 1999;113(5):483-485.

2. Gana P, Masterson L. Pleomorphic adenoma of nasal septum: a case report. J Med Case Report 2008;2:349.

3. Freeman SB, Kennedy KS, Parker GS, Tatum SA. Metastasizing pleomorphic adenoma of the nasal septum. Arch Otolaryngol Head Neck Surg 1990;116:1331-1333.

4. Unlu HH, Celik O, Demir MA, Eskiizmir G. Pleomorphic adenoma originated from inferior nasal turbinate. Auris Nasus Larynx 2003;30:417-420.

5. Pasquini E, Sciarretta V, Frank G, Cantaroni C, Modugno GC, Mazzatenta D, Farneti G. Endoscopic treatment of benign tumours of nose and paranasal sinuses. Otolaryngol Head and Neck Surg 2004;131:180-186.
6. Kumagai M, Endo S, Koizumi F, Kida A, Yamamoto M. A case of pleomorphic adenoma of nasal septum. Auris Nasus Larynx 2004;31:439-422.

7. TahlanA, NandaA, NagarkarN,Bansal S.Pleomorphicadenoma of thenasal septum: a case report. AmJ Otolaryngol 2004;25: 118-120.

8. Denker A, Kahler O. Handush der Hals. Nasen ohrenheikunde 1929;5:202.

9. Batsakis JG. Tumours of the Head and Neck. 2nd ed. Baltimore: Williams and Wilkins; 1984. p. 76-99.

10. Compagno J, Wong RT. Intranasal mixed tumours (pleomorphic adenomas): a clinicopathologic study of 40 cases. Am J Clin Pathol 1977;68:213-218.

11. Jackson LE, Rosenberg SI. Pleomorphic adenoma of lateral nasal wall. Otolaryngol Head Neck Surg 2002;127:474-476.

12. Avishay G, Yudith B, Milo F. Pleomorphic nasoseptal adenoma. J Otolaryngol 1997;26(6):399-401.

13. Rauchfuss A, Stadtler F. The differential diagnosis of benign neoplasms of the nasal septum. HNO 1981;29(4):124-127.

14. Shiyuti MI, Mohamad I, Sharif SET. Brunei Int Med J 2011;7 (5):300. 